\title{
Monoaminergic Dysfunction in Sjögren-Larsson Syndrome
}

\author{
Per Wester, ${ }^{1}$ Ullrica Bergström, ${ }^{1}$ ARne Brun, ${ }^{2}$ \\ STEN JAGELL, ${ }^{3}$ BERTIL KARLSSON, ${ }^{1}$ AND ANDERS ERIKSSON*.4 \\ 'Departments of Internal Medicine and 4Forensic Medicine, \\ University of Umeå, Ulmeå, Sweden; 'Department of Pathology, \\ University of Lund, Lund, Sweden; and 'Department of Pediatrics, \\ Gävle Hospital, Gävle, Sweden
}

Received December 5, 1990; Accepted March 29, 1991

\section{ABSTRACT}

The anteroposterior distribution of monoamine and monoamine metabolite concentrations was determined in subcortical brain nuclei of two cases of Sjogren-Larsson syndrome (SLS) and was compared to two control cases. The brains were divided into halves and sectioned coronally. For biochemical analyses, caudate nucleus, putamen, globus pallidus, substantia nigra, nucleus accumbens, amygdala, and hippocampus were dissected macroscopically. Monoamine and its metabolites were determined by reverse-phase liquid chromatography with electrochemical detection. The other hemisphere was studied neuropathologically.

The SLS cases revealed cell loss in substantia nigra and putamen and a widespread white-matter destruction. Biochemically, most pronounced alterations were seen in the dopamine system in putamen with severely reduced concentrations of dopamine (DA; $14 \%$ of control values) and the catabolic metabolites 3-methoxytyramine (3-MT; $9 \%$ of control values) and homovanillic acid (HVA; $20 \%$ of control values). In substantia nigra and the other striatal regions studied, a general decrease of 3-MT and HVA concentrations was observed in the SLS subjects compared to the controls, although the decrease was less pronounced than in putamen. Generally, somewhat reduced

*Author to whom all correspondence and reprint requests should be addressed. 
noradrenaline and 3-methoxy-4-hydroxyphenylglycol (MHPG) concentrations were seen in the SLS cases, whereas serotonin and 5-hydroxyindoleacetic acid (5-HIAA) concentrations were increased compared to the controls in most regions studied.

These data suggest a specific monoaminergic dysfunction in patients with SLS. The severe decline in the dopaminergic system in putamen suggests that supplementation of dopamine agonists may ameliorate the symptoms of SLS patients.

Index Entries: Sjögren-Larsson syndrome; human brain; monoamine; monoamine metabolite; monoaminergic dysfunction.

\section{ABBREVIATIONS}

L-Dopa: 3,4-dihydroxyphenylalanine

DA: dopamine

DOPAC: dihydroxyphenylacetic acid

3-MT: 3-methoxytyramine

HVA: homovanillic acid

NA: noradrenaline

MHPG: 3-methoxy-4-hydroxyphenylglycol
5-HT: 5-hydroxytryptamine

5-HIAA: 5-hydroxyindoleacetic acid

MAO: monoamine oxidase

COMT: catecholamine-O-methyltransferase

SLS: Sjögren-Larsson syndrome

\section{INTRODUCTION}

The Sjögren-Larsson syndrome (SLS) is characterized by mental retardation, spastic diplegia or tetraplegia, and congenital ichthyosis, with an autosomal recessive mode of inheritance (Sjögren and Larsson, 1957). All three cardinal symptoms are easily recognizable: the ichthyosis characteristic and the combination of symptoms unique. Along with the typical triad of symptoms, many patients have glistening white dots on the retina (Jagell et al., 1980). The motor symptoms vary from walking with aid to total immobility, and the mental retardation from mild but obvious with short sentence speech to severe with no speech (Jagell et al., 1981). Many patients also have seizures and exhibit short stature with kyphosis.

The syndrome has a worldwide distribution, but is particularly frequent in northern Sweden. Fifty-nine SLS patients are known from Sweden, and 35 of these are still alive (Jagell et al., 1981). In 1990, their mean age was $36 \mathrm{yr}$ and the oldest was $83 \mathrm{yr}$ of age (Jagell, unpublished observation). Only four patients have died during the last 20 years in Sweden; the two patients who died in 1988 were chosen for this study.

The etiology of SLS is not known, but deficient alcohol:nicotinamide-adenine dinucleotide oxidoreductase in cultured skin fibroblasts 
and peripheral blood leukocytes reduced to about $20 \%$ of normal has been observed (Rizzo et al., 1989).

The neurochemical features of SLS have not yet been characterized. In the present study, we present neurochemical data on two SLS cases compared to two controls.

\section{MATERIALS AND METHODS}

\section{Cases}

Two males with the typical signs characteristic of SLS (68 and $73 \mathrm{yr}$ old) and two males (67 and 74 yr old) without any previous known psychiatric or neurological disorder and dying from myocardial infarction were included. All included cases died a sudden, unexpected death with a fast agonal status (Hardy et al., 1985a). The interval between death and autopsy was 8 and $7 \mathrm{~h}$ for the SLS cases and 8 and $10 \mathrm{~h}$ for the controls.

The two SLS cases were both from a restricted area in northern Sweden where most Swedish SLS patients are born. They have earlier been reported as cases 17 and 21 by Jagell et al. (1981). They were typical SLS patients with average to pronounced severity of symptoms (Jagell et al., 1981).

The first SLS case (SLS I) was closely related to another SLS patient. He had had congenital ichthyosis since childhood. He was never able to walk without support, but was able to eat, dress, wash the upper part of his body, and move about in a wheelchair. He was mentally retarded, spoke with dysarthria, and did not learn to read or write. He had no seizures and, besides increasing joint contractures, there was no progression of his symptoms and he was in general good health until death.

The second SLS case (SLS II) had congenital ichthyosis and spastic diplegia since birth. He had severe mental retardation and could speak only a few words, but he was capable of following simple instructions. He was never able to walk on his feet. Instead, he moved about on his knees or in a wheelchair. He had attacks of seizures a few times monthly. At the age of 54 he showed Parkinsonian signs in his right arm. From the age of 60 he was no longer able to feed himself.

\section{Neuropathological Features}

The right hemisphere was fixed in formalin and studied neuropathologically in coronal whole hemispheral sections from paraffin blocks, the sections stained with various histopathological methods.

The first SLS case (SLS I) showed widespread partial loss of myelin and axons in the white matter plus small focal infarctions. The telencephalic cortex was not malformed, but showed a slight loss of neurons and an increase of astrocytes. The central gray nuclei were unremarkable 
except for putamen, where there was a mild astrocytic gliosis and multiple lacunar infarctions. Substantia nigra revealed a reduction of pigmented neurons with loss of pigment and interstitial gliosis. There was also a mild loss of cerebellar cortical neurons, a mild paling of posterior spinal cord fascicles, and some loss of myelin in the medial and lateral motor tracts.

The second SLS case (SLS II) showed widespread partial destruction of the white matter with reduction of axons and myelin sheaths together with mild astrocytic gliosis and macrophages containing myelin breakdown products. The whole striatal body showed a mild loss of neurons. The most striking degeneration was found in substantia nigra, with loss of many neurons and deposition of pigment in the interstitial tissue, which showed astrocytic gliosis. There was also a slight loss of cerebellar cortical neurons and a corresponding loss of nerve cells in the inferior olives, as well as a slight myelopathy with paling of posterior fascicles and, to some extent, of motor and spinal cerebellar tracts.

Neither of the SLS cases showed plaques, tangles, Lewy bodies, or Pick bodies. In the two control cases, no neuropathological changes were found.

\section{Brain Dissection for Biochemical Analyses}

The left hemisphere was used for biochemical assessment. The brainstem, cerebellum, and parts of neocortex were removed. The remaining tissue block was wrapped in airtight plastic film and immediately frozen at $-20^{\circ} \mathrm{C}$. Within $24 \mathrm{~h}$, the blocks were moved to a $-70^{\circ} \mathrm{C}$ freezer and stored there until sectioned. The sectioning procedure was performed in the frozen state, giving coronal slices $2.5 \mathrm{~mm}$ in thickness (Oke et al., 1978; Nyberg et al., 1983). Samples were dissected macroscopically using a small scalpel with the brain tissue frozen. Nucleus accumbens was defined as the fusing area of putamen and nucleus caudatus (Brockhaus, 1942). The specimens were placed in airtight Eppendorf tubes and immediately returned and kept at $-70^{\circ} \mathrm{C}$ until monoamine determination.

\section{Assessment of Monoamine Concentrations}

Concentrations of 3,4-dihydroxyphenylalanine (L-DOPA), dopamine (DA), 3-methoxytyramine (3-MT), homovanillic acid (HVA), noradrenaline (NA), 3-methoxy-4-hydroxyphenylglycol (MHPG), 5-hydroxytryptamine (5-HT), and 5-hydroxyindoleacetic acid (5-HIAA) were determined by reverse-phase liquid chromatography with electrochemical detection essentially as described elsewhere (Wester et al., 1987a,b). Briefly, frozen brain samples (ca. $80-100 \mathrm{mg}$ ) were weighed. To each $100 \mathrm{mg}$ of tissue, $700 \mu \mathrm{L}$ of $0.1 \mathrm{M}$ perchloric acid (containing $0.3 \mathrm{mM}$ $\mathrm{Na}_{2}$ EDTA and $\left.0.5 \mathrm{mM} \mathrm{NA} \mathrm{SO}_{2}\right), 70 \mu \mathrm{L}$ of $10^{-5} \mathrm{~mol} / \mathrm{L}$ isoproterenol (internal standard), and $70 \mu \mathrm{L}$ of concentrated heparin $(25,000 \mathrm{IE} / \mathrm{mL}$ ) 
were added. The tissue was then thoroughly disrupted by sonication by a Sonifier Cell Disrupter B-30 (Branson, Danbury, CT) on ice, continuous pulses set at 3.5 for $30 \mathrm{~s}$, and the suspension centrifuged at $48,000 \mathrm{~g}$ for 30 min at $+4^{\circ} \mathrm{C}$. The supernatant thus obtained was filtered through a 0.60 $\mu \mathrm{m}$ Millipore membrane filter and then injected directly into the chromatographic system. The isocratic mobile phase consisted of $100 \mathrm{mM}$ citrate buffer including $0.3 \mathrm{mM} \mathrm{Na}{ }_{2}$ EDTA, $0.334 \mathrm{mM}$ octylsulfate, and $5.5 / 94.5 \%$ $(\mathrm{v} / \mathrm{v})$ acetonitrile/water at a $\mathrm{pH}$ of 2.35 . The stationary phase consisted of a $170 \times 4.6 \mathrm{~mm}$ stainless steel column packed with Nucleosil C-18, $5 \mu \mathrm{m}$ (batch no. 5061) from Macherey-Nagel \& Co. KG (Düren, Germany); the column temperature was controlled by means of a plastic jacket (HPLCteknik HB, Robertsfors, Sweden) coupled to a water thermostat that was set at $+25^{\circ} \mathrm{C}$. The substances were detected electrochemically with a Coulochem ESA detector (Environmental Sciences Associates 5100A, Bedford, MA) with an analytical cell, model 7021. The detector was coupled to an integrator, model CI10 (Laboratory Data Control, Riviera Beach, FL). A guard cell (placed before the SIL 6A, Shimadzu autoinjector) was set at $1.05 \mathrm{~V}$ (to minimize background noise), the first detector cell at $0.10 \mathrm{~V}$ (to avoid a negative deflection in the baseline), and the second detector cell (coupled to the integrator) at $+0.55 \mathrm{~V}$. The flow rate was $1.2 \mathrm{~mL} / \mathrm{min}$.

\section{Data Analyses}

In order to perform comparisons between the SLS cases and the controls, data are presented as mean values of the transmitter and metabolite concentrations for the brain regions (each brain region consisting of 3-13 anteroposterior coronal slice measurements) and expressed as a percentage of control values.

\section{RESULTS}

In Tables 1-3 the mean concentrations of whole nuclei transmitter and metabolite concentrations are presented.

\section{Dopamine System (Table 1)}

In substantia nigra, the SLS cases showed reduced levels of the catecholamine precursor L-DOPA (44\% of control values), and nonreduced concentrations of DA (195\% of control values) and DOPAC ( $121 \%$ of control values). Concentrations of 3-MT and HVA were reduced (3-MT, 37\%, and HVA, 38\% of control values).

In putamen, there was observed in the SLS cases compared to the controls a severe decline of DA concentrations ( $14 \%$ of control values) as well as 3-MT ( $9 \%$ of control values) and HVA (20\% of control values) levels, whereas concentrations of L-DOPA and DOPAC were not re- 


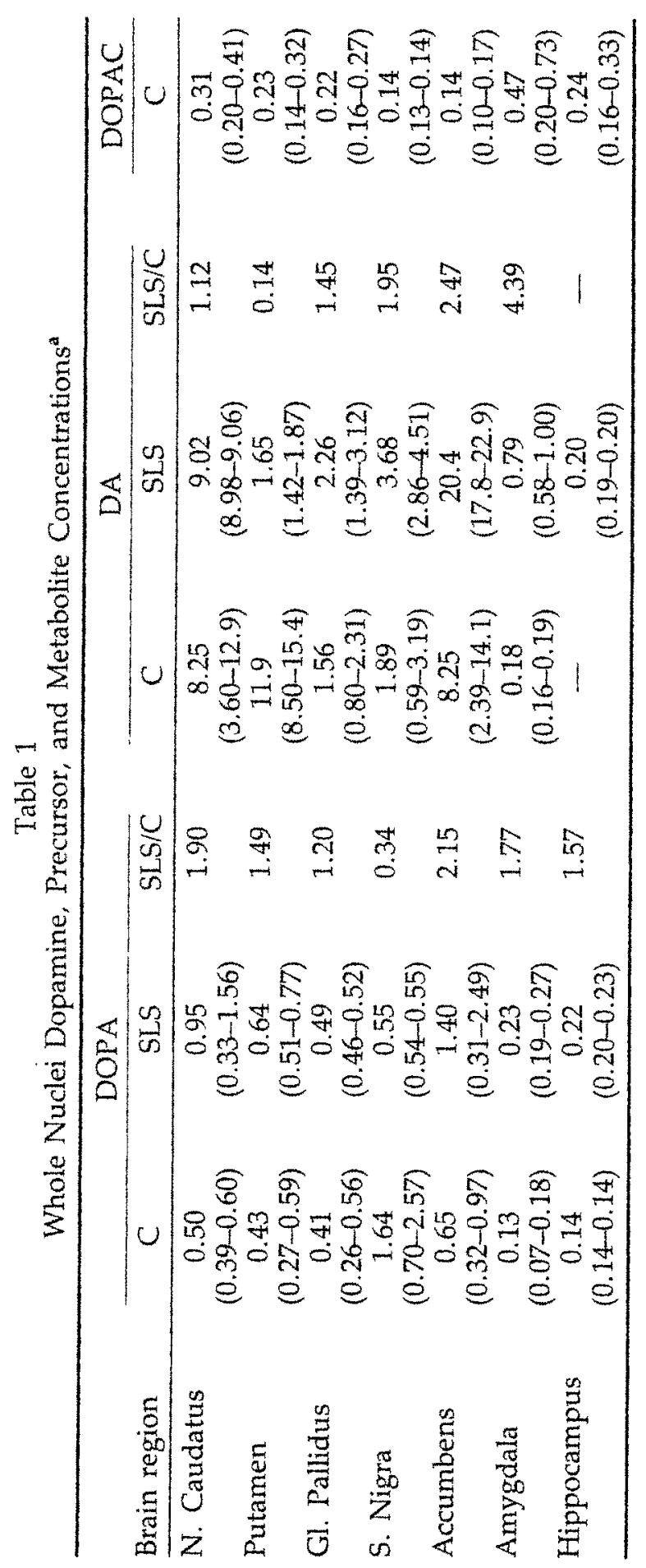




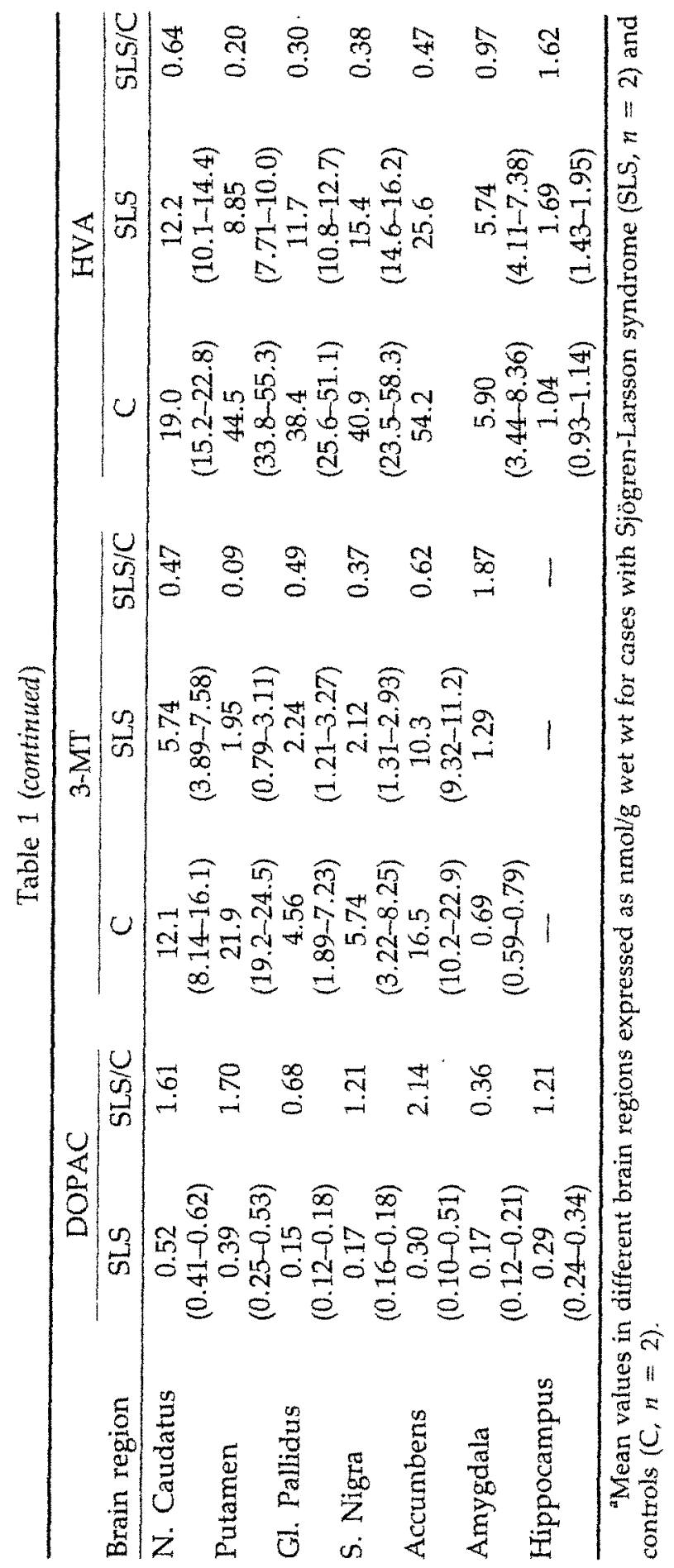


Table 2

Whole Nuclei Noradrenaline and Metabolite Concentrations ${ }^{\mathrm{a}}$

\begin{tabular}{|c|c|c|c|c|c|c|}
\hline \multirow[b]{2}{*}{ Brain region } & \multicolumn{3}{|c|}{$\mathrm{NA}$} & \multicolumn{3}{|c|}{ MHPG } \\
\hline & C & SLS & SLS/C & $\mathrm{C}$ & SLS & SLS/C \\
\hline N. Caudatus & $\begin{array}{c}0.88 \\
(0.77-0.98)\end{array}$ & $\begin{array}{c}0.68 \\
(0.57-0.79)\end{array}$ & 0.77 & 1.78 & 0.80 & 0.45 \\
\hline Putamen & $\begin{array}{c}0.97 \\
(0.91-1.03)\end{array}$ & $\begin{array}{c}0.79 \\
(0.57-1.01)\end{array}$ & 0.81 & 2.11 & 0.57 & 0.27 \\
\hline G1. Pallidus & $\begin{array}{c}0.84 \\
(0.53-1.15)\end{array}$ & $\begin{array}{c}0.85 \\
(0.59-1.04)\end{array}$ & 1.01 & 1.45 & 0.37 & 0.26 \\
\hline S. Nigra & $\begin{array}{c}2.07 \\
(1.06-3.08)\end{array}$ & $\begin{array}{c}1.41 \\
(1.05-1.77)\end{array}$ & 0.68 & 0.73 & 0.60 & 0.82 \\
\hline Accumbens & $\begin{array}{c}1.82 \\
(1.63-2.01)\end{array}$ & $\begin{array}{c}2.19 \\
(1.19-3.18)\end{array}$ & 1.20 & 2.09 & 0.64 & 0.31 \\
\hline Amygdala & $\begin{array}{c}1.69 \\
(1.46-1.92)\end{array}$ & $\begin{array}{c}1.00 \\
(0.67-1.33)\end{array}$ & 0.59 & 1.06 & 0.38 & 0.36 \\
\hline Hippocampus & $\begin{array}{c}0.89 \\
(0.87-1.02)\end{array}$ & $\begin{array}{c}0.45 \\
(0.44-0.46)\end{array}$ & 0.51 & 0.88 & 0.42 & 0.48 \\
\hline
\end{tabular}

Mean values in different brain regions expressed as nmol/g wet wt for cases with Sjögren-Larsson syndrome (SLS, $n=2$ ) and controls $(C, n=2$ ).

duced in the SLS cases (L-DOPA, 144\% and DOPAC, $170 \%$ of control values). In Fig. 1, the intranuclear distribution of the dopamine transmitter system in putamen is shown, exhibiting a fairly even, severely reduced anteroposterior distribution of transmitter and metabolites in the SLS cases compared to the controls.

In caudate nucleus, globus pallidus, and nucleus accumbens, a similar pattern was observed in the SLS cases for the DA transmitter system with nonreduced concentrations of L-DOPA (120-215\% vs control values), DA (112-247\% of control values), and DOPAC (121-214\%) vs controls except for globus pallidus, which had $68 \%$ of control values) and decreased concentrations of the metabolites 3-MT (49-63\% of control values) and HVA (30-64\% of control values).

In amygdala, a different pattern was observed for the DA system, with nonreduced concentrations of $\mathrm{L}$-DOPA (177\% vs control values), increased DA ( $439 \%$ vs control values), reduced DOPAC ( $36 \%$ vs controls), and nonreduced 3-MT (187\% vs control values) and HVA concentrations ( $97 \%$ vs control values) in the SLS cases.

\section{Noradrenaline System (Table 2)}

Reduced NA concentrations were observed in the SLS cases in most of the regions studied, exhibiting $50-80 \%$ of control values in hippocampus, amygdala, substantia nigra, putamen, and caudate nucleus, and nonreduced NA concentrations in globus pallidus and accumbens (101$120 \%$ of control values). Consistently, decreased MHPG concentrations were observed in the SLS cases (27-82\% of control values). 
Table 3

Whole Nuclei Serotonin and Metabolite Concentrations ${ }^{a}$

\begin{tabular}{|c|c|c|c|c|c|c|}
\hline \multirow[b]{2}{*}{ Brain region } & \multicolumn{3}{|c|}{ 5-HT } & \multicolumn{3}{|c|}{ 5-HIAA } \\
\hline & $\mathrm{C}$ & SLS & SLS/C & C & SLS & SLS/C \\
\hline N. Caudatus & $\begin{array}{c}1.20 \\
(0.94-1.46)\end{array}$ & $\begin{array}{c}1.08 \\
(1.06-1.10)\end{array}$ & 0.90 & $\begin{array}{c}1.97 \\
(1.14-1.80)\end{array}$ & $\begin{array}{c}3.95 \\
(1.06-1.10)\end{array}$ & 2.00 \\
\hline Putamen & $\begin{array}{c}1.14 \\
(0.92-1.36)\end{array}$ & $\begin{array}{c}2.02 \\
(1.70-2.34)\end{array}$ & 1.77 & $\begin{array}{c}3.23 \\
(2.05-4.41)\end{array}$ & $\begin{array}{c}8.44 \\
(5.57-11.3)\end{array}$ & 2.61 \\
\hline Gl. Pallidus & $\begin{array}{c}0.84 \\
(0.63-1.04)\end{array}$ & $\begin{array}{c}1.64 \\
(1.04-2.23)\end{array}$ & 1.95 & $\begin{array}{c}4.76 \\
(3.15-6.37)\end{array}$ & $\begin{array}{c}10.4 \\
(4.58-16.1)\end{array}$ & 2.18 \\
\hline S. Nigra & $\begin{array}{c}3.19 \\
(1.40-4.98)\end{array}$ & $\begin{array}{c}5.21 \\
(4.74-5.69)\end{array}$ & 1.63 & $\begin{array}{c}14.5 \\
(11.4-17.1)\end{array}$ & $\begin{array}{c}16.3 \\
(12.1-20.5)\end{array}$ & 1.12 \\
\hline Accumbens & $\begin{array}{c}1.84 \\
(0.91-2.76)\end{array}$ & $\begin{array}{c}2.22 \\
(2.07-2.37)\end{array}$ & 1.21 & $\begin{array}{c}6.25 \\
(4.33-8.17)\end{array}$ & $\begin{array}{c}9.00 \\
(7.72-10.3)\end{array}$ & 1.44 \\
\hline Amygdala & $\begin{array}{c}0.93 \\
(0.89-0.97)\end{array}$ & $\begin{array}{c}1.16 \\
(1.16-1.16)\end{array}$ & 1.25 & $\begin{array}{c}3.40 \\
(2.76-4.03)\end{array}$ & $\begin{array}{c}6.91 \\
(3.36-10.4)\end{array}$ & 2.03 \\
\hline Hippocampus & $\begin{array}{c}0.46 \\
(0.35-0.57)\end{array}$ & $\begin{array}{c}0.49 \\
(0.40-0.57)\end{array}$ & 1.06 & $\begin{array}{c}1.42 \\
(1.16-1.68)\end{array}$ & $\begin{array}{c}2.91 \\
(1.96-3.85)\end{array}$ & 2.05 \\
\hline
\end{tabular}

${ }^{a}$ Whole brain regions (mean and range) in nmolg wet wt for cases with Sjögren-Larsson syndrome (SLS, $n=2$ ) and controls $(C, n=2$ ).

\section{Serotonin System (Table 3)}

Increased 5-HT concentrations were observed in the SLS cases in the regions investigated (121-195\% of control values) except for caudate nucleus and hippocampus (90-106\% of control values). 5-HIAA concentrations were also increased in the SLS cases in all regions investigated, with values ranging from $112-260 \%$ of controls.

\section{DISCUSSION}

In the control brains, the regional distribution and the concentrations of the monoamine transmitter and transmitter metabolites measured in this study in postmortem human brain were mostly in the range of earlier studies (MacKay et al., 1978; Carlsson et al., 1980; Nyberg et al., 1983, 1985; Wester et al., 1984, 1987b, 1990; Morgan et al., 1987). In one of the controls, however, somewhat low dopamine concentrations were found, especially in caudate nucleus and substantia nigra (Table 1), whereas concentrations of the dopamine metabolites were in the range of previous reports (see refs. listed above). Moreover, the intranuclear distribution of catecholamines in the controls was similar to that reported previously (Nyberg et al., 1983; 1985). Since the SLS cases and the controls were matched for sex, age, interval between death and autopsy, and agonal status, these factors should not have biased the results (cf Carlsson and Winblad, 1976; Hardy et al., 1985a; Wester, 1987). However, the data have to be considered with caution, since the number of cases is low and the biochemical variables show relatively large variation. 

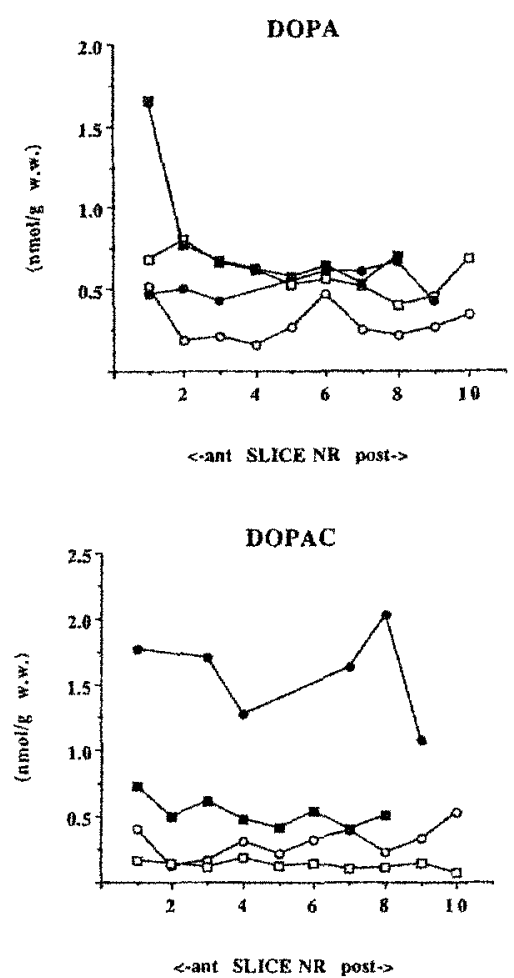
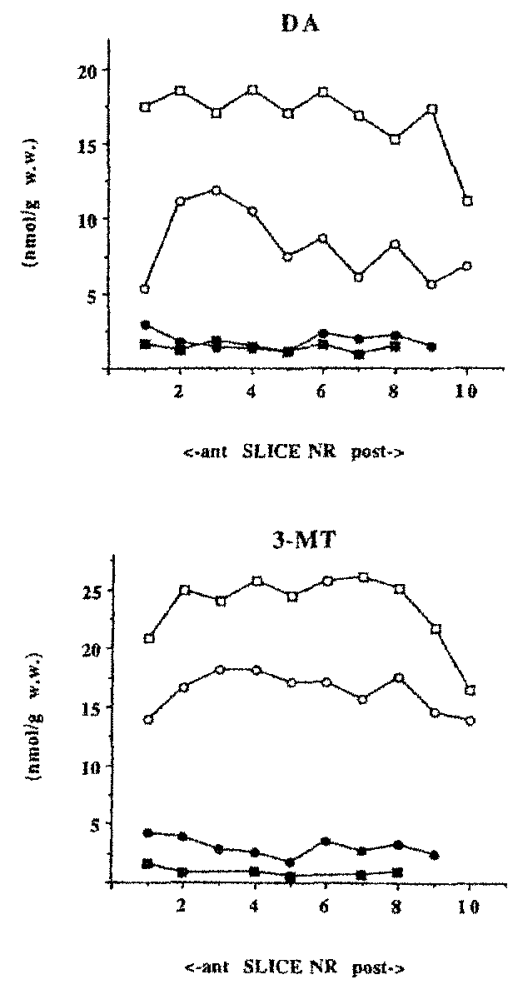

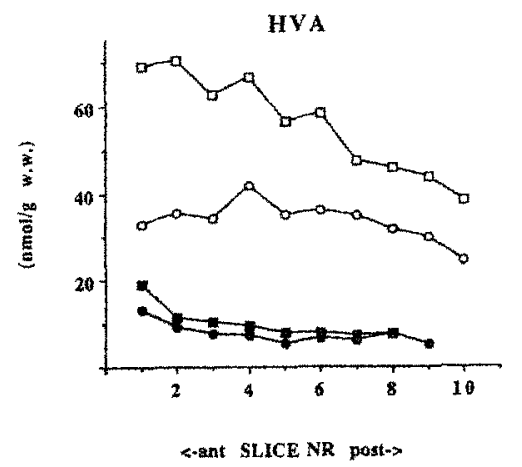

Fig. 1. The anteroposterior distribution of the concentrations of 3,4-dihydroxyphenylalanine (DOPA), dopamine (DA), dihydroxyphenylacetic acid (DOPAC), 3-methoxytyramine (3-MT), and homovanillic acid (HVA) in putamen for two cases with Sjögren-Larsson syndrome (SLS I and SLS II) and two controls (C I and C II). Values are given as nmol/g wet wt. The chromatographic conditions and the sampling handling procedure are described in Materials and Methods. $\longrightarrow, \mathrm{Cl} ;-\longrightarrow, \mathrm{CI} ; \longrightarrow$ SLS I; $\longrightarrow$, SLS II. 


\section{Dopamine System}

The major finding in this study was the drastic decline of the dopamine system in putamen in the SLS cases, which has not been reported previously. Thus, in putamen in the SLS cases, severe reduction of DA and its metabolites (DA, 14\%; 3-MT, 9\%; HVA, 20\% vs controls) were seen. Moreover, less pronounced decrease of 3-MT and HVA concentrations were found in substantia nigra as well as in the other striatal regions studied, although DOPAC concentrations were not decreased. Furthermore, the histopathological examination in the present study revealed a cell loss in the substantia nigra and in putamen in the SLS cases. This is in accordance with the clinical picture of one of the SLS patients exhibiting Parkinsonian signs in his right arm. Thus, taken together, these data indicate that the neurons most severely affected in SLS seem to be in putamen and substantia nigra, suggesting a specific vulnerability of the nigrostriatal DA system that specifically projects from the caudal and lateral parts of zona compacta (A9) in substantia nigra to putamen (Dahlström and Fuxe, 1964; Ungerstedt, 1971; Moore and Bloom, 1978). However, a different biochemical pattern of dopaminergic disturbance was observed in these two regions. Hence, in substantia nigra, decreased concentrations were observed of the monoamine precursor L-DOPA as well as the catabolic DA metabolites 3-MT and HVA, whereas the DA levels were not decreased. In contrast, in putamen, L-DOPA concentrations were not decreased, whereas concentrations of DA, 3-MT, and HVA were severely reduced.

These data could be explained by one of the following theories, or a combination of them:

\section{Monoamine Enzyme Dysfunctions}

The results could be implicated as specific dysfunctions of different anabolic and catabolic monoamine enzymes in the SLS cases, which in turn may be a consequence of disorders in the SLS genome (Sjögren and Larsson, 1957).

In substantia nigra, the reductions of 3-MT and HVA concentrations may be a result of a disturbance in the preferentially extraneuronally located catabolic enzyme catechol-o-methyltransferase (COMT) activity (Kopin et al., 1972; Cooper et al., 1986). The disturbed COMT activity, as hypothesized, would inhibit an increased presynaptic nigrostriatal dopaminergic turnover, such as that occuring in the compensatory stage of Parkinson's disease (Hornykiewicz and Kish, 1986). This may explain the nonreduced DA levels in substantia nigra as measured in this study. The nonreduced DA levels in substantia nigra, in turn, may act via a negative feedback mechanism on the normally rate-limiting anabolic enzyme tyrosine hydroxylase activity (Levitt et al., 1965; Cooper et al., 1986), leading to low L-DOPA levels. Alternatively, a primary disturbance in tyrosine hydroxylase activity could explain the low L-DOPA concentrations in substantia nigra. 
In putamen, the severely reduced DA concentrations may be attributed, to some degree, to an aromatic L-amino acid decarboxylase deficit in the SLS cases. The low DA levels could act presynaptically via a positive feedback loop mechanism on tyrosine hydroxylase activity (Levitt et al., 1965; Cooper et al., 1986) leading to nonreduced L-DOPA levels in putamen. The low DA concentrations and/or a COMT activity disturbance may explain the low 3-MT and HVA levels in putamen.

In amygdala that belongs to the mesolimbic DA system (Björklund and Lindvall, 1984), a somewhat different pathological pattern was observed in the SLS cases. Hence, concentrations of L-DOPA were not reduced, DA increased, DOPAC decreased, and 3-MT and HVA not reduced in the SLS cases compared to the controls. These data could be interpreted as an effect of a disturbance in the preferentially intraneuronally active enzyme monoamine oxidase (MAO) activity (Kopin, 1972; Cooper et al., 1986), which in turn could be attributed to a disturbed presynaptic transmission compensated by a transmitter release operating at an accelerated rate.

In addition, contributing to the anabolic and catabolic enzyme dysfunctions as hypothesized might be enzyme cofactor disturbances: Thus, a dysfunction of dihydropteridine reductase in brain could alter the cofactor tetrahydropteridine necessary for tyrosine- $\beta$-hydroxylase activity; a disturbed uptake to the brain of pyridoxalphosphate (vitamin $B_{6}$ ) could alter the activity of aromatic L-amino acid decarboxylase, whereas COMT activity could be altered by a deficiency of S-adenosylmethionine and $\mathrm{Mg}^{2+}$ (e.g., Mayer, 1980; Cooper et al., 1986).

However, the theory of anabolic and catabolic monoamine enzyme dysfunctions as suggested in SLS needs confirmation, e.g., by directly measuring the activities of these enzymes in brain tissue of SLS cases.

\section{Primary Neuronal Degeneration}

The dopaminergic deficiency in putamen in SLS could be caused by a primary idiopathic nigrostriatal dopaminergic degeneration with cell loss in substantia nigra and in striatum, in accordance with the findings in Parkinson's disease (Birkmeyer and Hornykiewicz, 1961; Hornykiewicz, 1972; Bernheimer et al., 1973; Nyberg et al., 1983; Hornykiewicz and Kish, 1986) and to a somewhat lesser extent in nonpathological aging (Carlsson and Winblad, 1976; Carlsson et al., 1980; Morgan et al., 1987). Interestingly, a similar regional biochemical disturbance has been reported in Parkinson's disease for the DA system, with putamen by far most severely affected with DA concentrations $<10 \%$ of control values while caudate nucleus (Nyberg et al., 1983; Kish et al., 1988) and accumbens (Nyberg et al., 1983) showed more gentle DA reductions. Putamen has been proposed to be primarily involved in movement control (Crutcher and DeLong, 1984a, b) as a part of the corticosubcortical motor-loop system (Evarts et al., 1984). In Parkinson's disease, a nigrostriatal DA loss exceeding $80 \%$ is considered to cause a decompensation stage (Horny- 
kiewicz and Kish, 1986) with the severity of clinical symptoms positively correlated to the degree of striatal DA loss (Bernheimer et al., 1973). Thus, the pronounced DA deficiency in putamen in the SLS cases reported in this study, surpassing the nigrostriatal compensatory capacity, may in part explain the extrapyramidal symptoms in SLS, i.e., the spastic di/ tetraplegia.

\section{Noradrenaline System}

The widespread observed reduced concentrations of NA and MHPG in the SLS cases measured in this study could also be explained by the anabolic enzymatic dysfunction theory described above, as well as by a primary neuronal degeneration. The NA deficiency reported in the present study has some features in common with other neuropathological diseases. Thus, in Parkinson's disease, a noradrenergic deficit has been reported (Hornykiewicz, 1972; Mann and Yates, 1983; Hornykiewicz and Kish, 1986), although not consistently (Kopp et al., 1982), as well as a NA reduction in Alzheimer's disease (for reviews of dementia conditions, see Hardy et al., 1985b).

\section{Serotonin System}

The findings in the present study of increased 5-HT and 5-HIAA levels in the SLS are not consistent either with the findings in Parkinson's disease or with those in Alzheimer's disease, in which a moderate serotonergic deficit is established (Hornykiewicz, 1972; Hardy et al., 1985b; Hornykiewicz and Kish, 1986). Since 5-HT is preferentially catabolized to 5-HIAA by monoamine oxidase type B (MAO-B) (Cooper et al., 1986), a difference between the MAO-A and MAO-B activities in SLS could explain the present findings with increased 5-HIAA and decreased HVA concentrations in the SLS cases. Thus, according to the enzyme dysfunction theory in SLS, increased MAO-B and decreased MAO-A activities are suggested.

In conclusion, in the SLS cases studied, pronounced alterations were seen in the dopamine sytem in putamen, with severely reduced concentrations of DA, 3-MT, and HVA. Reduced noradrenaline and MHPG concentrations and increased levels of serotonin and 5-HIAA were observed in the SLS cases compared to the controls in most regions studied. These data suggest a specific monoaminergic dysfunction in SLS. The dopaminergic deficiency in putamen in SLS may be ameliorated by supplementation of DA agonists.

\section{ACKNOWLEDGMENTS}

The authors wish to thank Olle Magnusson for fruitful discussion. This study was supported by the Swedish Heart and Lung Foundation, King Gustaf V's 80th Anniversary Foundation, Tore Nilsson's and Stohne's Funds in Sweden and the Swedish Society of Medicine. 


\section{REFERENCES}

Bernheimer H., Birkmayer W., Hornykiewicz O., Jellinger K., and Seitelberger. F. (1973) Brain dopamine and the syndromes of Parkinson and Huntington. J. Neurol. Sci. 20, 415-455.

Birkmeyer W. and Hornykiewicz O. (1961) Der L-dioxyphenylalanin (=LDOPA)-Effekt bei der Parkinson-Akinesi. Wien. Klin. Wochenschr. 73, 787788.

Björklund A. and Lindvall O. (1984) Dopamine-containing systems in the CNS, in Handbook of Chemical Neuroanatomy (Björklund A. and Hökfeldt T., eds.), vol. 2. Elsevier, Amsterdam.

Brockhaus H. (1942) Eine einfache Schnellmethode zur Darstellung der senilen Drusen Z. Ges. Neurol., Band 51, heft 1, u.2.

Carlsson A. and Winblad B. (1976) Influence of age and time interval between death and autopsy on dopamine and 3-methoxytyramine levels in human basal ganglia. J. Neural Transm. 38, 271-276.

Carlsson A., Adolfsson R., Aquilonius S. -M., Gottfries C. -G., Oreland L., Svennerholm L., and Winblad B. (1980) Biogenic amines in human brain in normal aging, senile dementia, and chronic alcoholism, in Ergot Compounds and Brain Function: Neuroendocrine and Neuropsychiatric Aspects (Goldstein M. et al., eds.), pp. 295-304, Raven, New York.

Cooper J. R., Bloom F. E., and Roth R. H. (1986) The Biochemical Basis of Neuropharmacology, 5th Ed. (Oxford University Press, New York).

Crutcher M. D. and DeLong M. R. (1984a) Singe cell studies of the primate putamen. I. Functional organization. Exp. Brain Res. 53, 233-243.

Crutcher M. D. and DeLong M. R. (1984b) Single cell studies of the primate putamen. II. Relations to direction of movement and pattern of muscular activity. Exp. Brain Res. 53, 244-258.

Dahlström A. and Fuxe K. (1964) Evidence for the existence of monoaminecontaining neurons in the central nervous system. I. Demonstration of monoamines in the cell bodies of the brain stem neurons. Acta Physiol. Scand. 62, (Suppl. 232), 1-55.

Evarts E. V., Kimura M., Wurtz R. H., and Hikosaka O. (1984) Behavioural correlation of activity in basal ganglia neurons. Trends Neurosci. 7, 369-386.

Hardy J. A., Wester P., Winblad B., Gezelius C., Bring G., and Eriksson A. (1985a) The patients dying after long terminal phase have acidotic brains: Implications for biochemical measurements on autopsy tissue. J. Neural Transm. 61, 253-264.

Hardy J., Adolfsson R., Alafuzoff I., Bucht G., Marcusson J., Nyberg P., Perdahl E., Wester P., and Winblad B. (1985b) Transmitter deficits of Alzheimer's disease. Neurochem. Int. 7, 545-563.

Hornykiewicz O. (1972) Neurochemistry of parkinsonism, in Handbook of Nettrochemistry (Lajtha A., ed.), vol. 5, p. 465, Plenum, New York.

Hornykiewicz O. and Kish S. J. (1986) Biochemical pathophysiology in Parkinson's disease. Adv. Neurol. 45, 19-34.

Jagell S., Gustavson K. H., and Holmgren G. (1981) Sjögren-Larsson syndrome in Sweden: A clinical, genetic and epidemiological study. Clin. Genet. 19, 233. 
Jagell S., Polland W., and Sandgren O. (1980) Specific changes in the fundus typical for the Sjögren-Larsson syndrome. Acta Ophtal. Scand. 58, 321-329.

Kish S. J., Shannak K., and Hornykiewicz O. (1988) Uneven pattern of dopamine loss in the striatum of patients with idiopathic Parkinson's disease: Pathophysiologic and clinical implications. N. Engl. J. Med. 318, 876-880.

Kopin I. J. (1972) Metabolic degradation of catecholamines. The relative importance of different pathways under physiological conditions and after administration of drugs, in Catecholamines (Blaschko M. and Muscholl E., eds.) Handbuch der Experimentellen Pharmakologie, vol. 33, pp. 271-282, SpringerVerlag, Berlin.

Kopp N., Denoroy L., Tommasi M., Gay N., Chazot G., and Renaud B. (1982) Increase in noradrenaline-synthesizing enzyme activity in medulla oblongata in Parkinson's disease. Acta Neuropathol. (Berl.) 56, 17-21.

Levitt M., Spector S., Sjoerdsma A., and Udenfriend S. (1965) Elucidation of the rate-limiting step in norepinephrine biosynthesis in the perfused guinea pig heart. I. Pharmacol. Exp. Ther. 148, 1-8.

MacKay A. V. P., Yates C. M., Wright A., Hamilton P., and Davies P. (1978) Regional distribution of monoamines and their metabolites in the human brain. J. Neurochem. 30, 841-848.

Mann D. M. A. and Yates P. O. (1983) Pathological basis for neurotransmitter changes in Parkinson's disease. Neuropathol. Appl. Neurobiol. 9, 3-19.

Mayer S. E. (1980) Neurohumoral transmission and the autonomic nervous system, in The Pharmacological Basis of Therapeutics (Goodman Gilman A., Goodman L. S., and Gilman A. eds.), pp. 56-90, MacMillan, New York.

Moore R. Y. and Bloom F. E. (1978) Central catecholamine neuron systems: Anatomy and physiology of the dopamine systems. Annu. Rev. Neurosci. 1, 129-169.

Morgan D. G. Marcusson J. O., Nyberg P., Wester P., Winblad B., Gordon M. N., and Finch C. E. (1987) Divergent changes in D-1 and D-2 dopamine binding sites in human basal ganglia during normal aging. Neurobiol. Aging 8, 195-201.

Nyberg P., Nordberg A., Wester P., and Winblad B. (1983) Dopaminergic deficiency is more pronounced in putamen than in nucleus caudatus in Parkinson's disease. Neurochem. Pathol. 1, 193-202.

Nyberg P., Adolfsson R., Hardy J. A., Nordberg A., Wester P., and Winblad B. (1985) Catecholamine topochemistry in human basal ganglia. Comparison between normal and Alzheimer brains. Brain Res. 333, 139-142.

Oke A., Keller R., Mefford I., and Adams R. N. (1978) Lateralization of norepinephrine in human thalamus. Science 200, 1411-1413.

Rizzo W. Dammanss A. L., Craft D. A., Black S. H., Henderson Tilton A., Africk D., Chaves-Carballo E., Holmgren G., and Jagell S. (1989) SjögrenLarsson syndrome: Inherited defect in the fatty alcohol cycle. J. Pediatr. 115, 228-234.

Sjögren T. and Larsson T. (1957) Oligophrenia in combination with congenital ichthyosis and spastic disorders. Acta. Psychiatr. Neurol. Scand. 32 (Suppl. $113), 1-113$.

Ungerstedt U. (1971) Stereotaxic mapping of the monoamine pathways in the rat brain. Acta Physiol. Scand. (Suppl.) 367, 1-48. 
Wester P. (1987) Monoamine neurotransmitters in human brain and cerebrospinal fluid. Methodological, functional and clinical studies. Umeå university medical dissertations. Umeå, Sweden.

Wester P., Gottfries J., and Winblad B. (1987b) Simultaneous liquid chromatographic determination of seventeen of the major monoamine neurotransmitters, precursors and metabolites II. Assessment of human brain and cerebrospinal fluid concentrations. J. Chromatogr. 415, 275-288.

Wester P., Gottfries J., Johansson K., Klintebäck F., and Winblad B. (1987a) Simultaneous liquid chromatographic determination of seventeen of the major monoamine neurotransmitters, precursors and metabolites I. Optimization of the mobile phase using factorial designs and a computer program to predict chromatograms. f. Chromatogr. 415, 261-274.

Wester P., Hardy J. A., Marcusson J., Nyberg P., and Winblad B. (1984) Serotonin concentrations in normal aging human brains: Relation to serotonin receptors. Neurobiol. Aging 5, 199-203.

Wester P., Bergström U., Eriksson A., Gezelius C., Hardy J., and Winblad B. (1990) Ventricular monoamine and monoamine metabolite concentrations reflect human brain neurochemistry in autopsy cases. I. Neurochem. 54, 1148-1156. 